\title{
Podcasts as emerging tool for medical education: a critical perspective
}

\author{
Radhika Vijay ${ }^{1 *}$, Namita Gupta ${ }^{2}$
}

\author{
${ }^{1}$ Department of Pharmacology, S. P. Medical College, Bikaner, Rajasthan, India \\ ${ }^{2}$ Forest Research Institute Deemed University, Dehradun, Uttarakhand, India
}

Received: 02 October 2021

Revised: 31 October 2021

Accepted: 01 November 2021

\author{
*Correspondence: \\ Dr. Radhika Vijay, \\ Email: drradhika_vijay@yahoo.in
}

Copyright: (C) the author(s), publisher and licensee Medip Academy. This is an open-access article distributed under the terms of the Creative Commons Attribution Non-Commercial License, which permits unrestricted non-commercial use, distribution, and reproduction in any medium, provided the original work is properly cited.

\begin{abstract}
Background: Podcasts have started knocking the educational doors after setting their feet strong in entertainment grounds. There has always been a trend to welcome and introduce new ideas and innovative ways in medical education for the benefit of students. No doubts, they are an emerging tool for education. The study aims to know and evaluate critically the students' perspective about the novel aural technology and its relevance to be included in the curriculum.

Methods: A sample size of 110 undergraduate medical students enrolled in two private post graduate coaching centres in metropolitan regions of Delhi was taken to conduct the study. A semi structured pen and paper questionnaire was created and made to be filled by the participants.

Results: Aware students actively participated in the survey and shared their preferences and opinions, but many lacked knowledge and interest in the newly introduced and conveyed audio technology. This was a direct result of their surroundings, friends and family circle. Generally, there was a welcome response towards podcasts being in trend and to be included as a supplementary teaching tool along with present ongoing modes of education.

Conclusions: Students' opinion taken over from time to time is of great value to introduce modern educational reforms. Podcasts are a very effective add-on tool if introduced in medical education. There still exists a wide room for research and evidence-based use of this technology and much work needs to be done to actually add a new brick in the current structure of medical education.
\end{abstract}

Keywords: Podcasts, Medical education, Perspective, Teaching-learning

\section{INTRODUCTION}

Podcasts have started knocking the educational doors after setting their feet strong in entertainment grounds. There has always been a trend to welcome and introduce new ideas and innovative ways in medical education for the benefit of students. Technology is advancing at the pace of light, though much in vogue in foreign countries, podcasts are being listened to in India too. No doubts, they are an emerging tool for education. There are podcasts for every language and age. In this study, special focus is laid on the essence of aural education as a supplement to ongoing teaching methodologies. It is important to understand and know the medical students' point of view in our Indian setup regarding this novel technology involving interplay of human voice and hearing mechanism. This will help empower teaching skills and learning methods and will pave the way to adopt better, enriched integrative methods in medical education to build a strong, learned society of doctors in all subjects.

Podcasts is not a new term, it's a portmanteau formed by combining "ipod" and "broadcast", used firstly by Ben Hammersley, the Guardian columnist and BBC journalist ${ }^{1}$. It was chosen by Oxford dictionary as "word 
of the year" in 2005. ${ }^{1-3}$ There have been many studies conducted in the past to know its impact on medical education but in lack of strong guidelines and evidence, proper integration of this technology and methodology still needs to be worked upon. ${ }^{4-10}$ Podcasts are defined as digital audio/video files uploaded as a series of topics and can be downloaded from the internet on mobile app/ media. ${ }^{3,4,11-15}$

Historically, it's evident that education has been modernized with touch of technology, as by end of 1970s, computer was in, since then, colors of tech and trend have made education modes diversified and versatile and much more useful for the masses, we still cannot ignore the growing demands of education system as time advances and Podcast is surely another learning enhancement tool! $!^{4,6,11,16-20}$

\section{Aim of study}

Aim of current study was to know how many students know about podcasts and listen to them and to collect and evaluate students' point of view regarding relevance and inclusion of podcasts in current medical education.

\section{METHODS}

An empirical, descriptive, cross-sectional questionnairebased survey was performed in the metropolitan region of National capital territory (NCT) of Delhi from June 2021 to July 2021. A sample size of 110 undergraduate medical students (comprising first, second and final year) enrolled in two private post graduate coaching centres was taken to conduct the study. ${ }^{10} \mathrm{~A}$ semi structured questionnaire was prepared and distributed by convenient random sampling ${ }^{21}$ to students. Students were made to fill the questionnaire form after taking prior informed consent from them. Responses were collected on the spot or flexibly in person, on mail or phone within the duration of one month. 48 responses were obtained from one centre while 62 responses were received from another centre.

\section{Inclusion criteria}

Total of 110 undergraduate students participated in study. They were a mix of first, second and final year of MBBS curriculum. All the students who were enrolled in private coaching centres, who gave the informed consent and those who filled the questionnaire during study time duration were included in the study.

\section{Exclusion criteria}

All the undergraduate students who were not enrolled in private coaching centres, who did not give informed consent and who did not fill the questionnaire were excluded from the study.

\section{Data analysis}

Pen and paper questionnaire was created; its validity was determined by expert opinion and suggestion (Table 1). It consisted of four parts namely demographic details, students' basic knowledge and interest in podcasts, knowledge of family members about podcasts, students' attitude, opinion and rating about podcast experience.

Table 1: Questionnaire (without answer options).

\begin{tabular}{|l|}
\hline Questions \\
\hline Informed consent \\
\hline Name of participant \\
\hline Age of participant \\
\hline City of residence \\
\hline Male/female \\
\hline Preferred learning mode \\
\hline Do you know about podcasts? \\
\hline From where did you get to know about Podcasts? \\
\hline Do you listen to podcasts? \\
\hline Which podcast category do you listen to? \\
\hline Name your favorite podcast or artist. \\
\hline Which educational podcast do you know about? \\
\hline Has any query been solved by listening to podcasts? \\
\hline $\begin{array}{l}\text { Do your family members or friends listen to } \\
\text { podcasts? }\end{array}$ \\
\hline Which podcast do they listen to? \\
\hline Do you think podcasts are in trend? \\
\hline $\begin{array}{l}\text { Is listening to podcasts better than watching a } \\
\text { video? }\end{array}$ \\
\hline $\begin{array}{l}\text { Do you think podcasts should be included in the } \\
\text { medical education curriculum? }\end{array}$ \\
\hline Do you use headphones to listen to podcasts? \\
\hline What can be possible side effects of podcasts? \\
\hline Rate podcast experience. \\
\hline
\end{tabular}

Responses were entered manually in a master chart built in Microsoft excel. Responses were analyzed and made into distinct sorted charts and tables pertaining to different questions. Prevalence was reported as ratios and percentages.

\section{RESULTS}

\section{Demographic characteristics of students}

Amongst 110 students who responded, 55 students (50\%) were males and 55 students $(50 \%)$ were females. As far as age groups are concerned, 10 students were 21 years old, 20 students were 22 years old, 10 students were 23 years old, 15 students were 24 years old, 20 students were 25 years old, 20 students were 26 years old, 15 students were 27 years old. Average age of sample was 24.22. Students belonged to different cities of residence all over the country. Maximum students $(18.2 \%)$ were from New Delhi followed by Pune (13.6\%), Mumbai (9.1\%), Gangtok (9.1\%), Chandigarh $(9.1 \%)$, Agra (9.1\%), 
Shimla (9.1\%), Chennai (9.1\%), Kolkata (9.1\%) and Visakhapatnam (4.5\%).

\section{Students' basic knowledge and interest in podcasts}

This set consisted of questions 6 to 12.These questions were especially framed to judge the basic knowledge and interest of students in this novel podcast technology. Students were asked first and foremost about their preferred mode of learning in which maximum students opted for audio and video (77.2\%) followed by self reading $(13.6 \%)$, offline traditional methodology $(4.5 \%)$ and only video (4.5\%) (Figure 1).

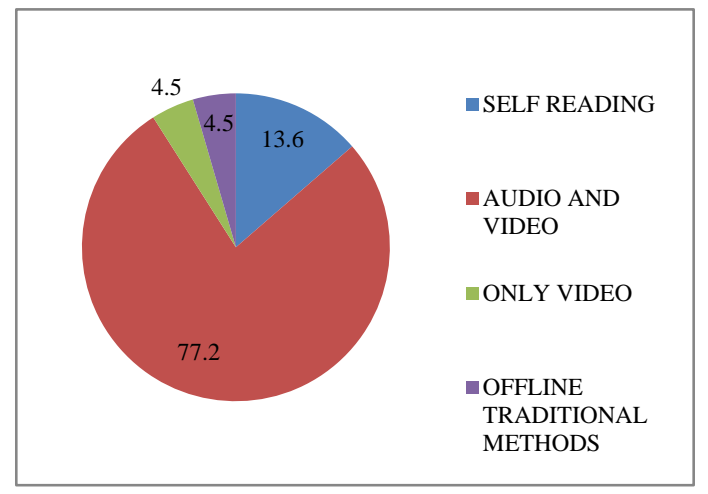

Figure 1: Preferred mode of learning by the students.

Next, students were inquired if they have heard or know about podcasts. 60 students $(54.5 \%)$ did not know and 50 students $(45.4 \%)$ knew about the term podcasts (Table 2).

Table 2: Students' knowledge about podcast.

\begin{tabular}{|ll|}
\hline Students' knowledge of podcast & Percentage \\
\hline Know podcast & 45.5 \\
\hline Don't know about podcast & 54.5 \\
\hline
\end{tabular}

When asked about the source of knowledge about podcasts, 55 students $(50 \%)$ said that they got to know from friends, 35 students $(31.8 \%)$ got the knowledge from internet, 10 students $(9 \%)$ got to know from social media like whatsapp, instagram, facebook, twitter, etc, 5 students $(4.5 \%)$ got their knowledge from magazine and 5 students $(4.5 \%)$ did not respond at all (Figure 2).

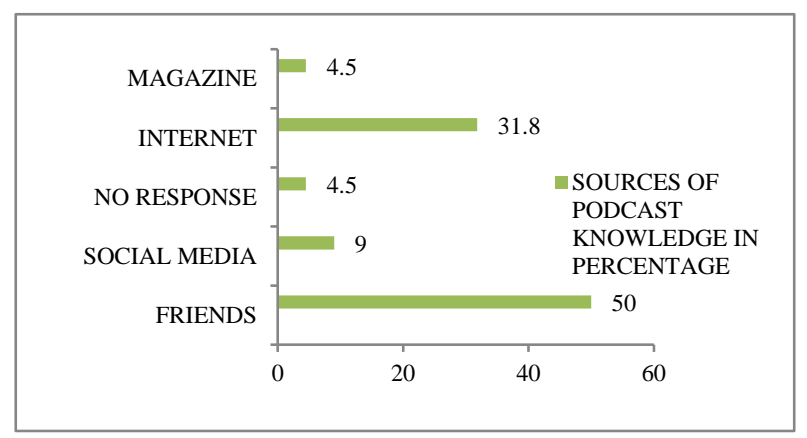

Figure 2: Sources of knowledge of podcasts.
Next students were asked if they actually listened to the podcasts, then 60 students $(54.5 \%)$ refused while 50 students $(45.4 \%)$ agreed. Students were inquired about category of podcasts they listened to, 10 students (9\%) listened to education podcasts, 10 students $(9 \%)$ replied that there is no specific category of podcasts, 5 students $(4.5 \%)$ listened to self help podcasts, 5 students $(4.5 \%)$ listened to motivation podcasts, 5 students (4.5\%) listened to business/science/history podcast, 5 students $(4.5 \%)$ listened to entertain-ment podcasts and 5 students $(4.5 \%)$ listened to music and stories podcasts. 60 students $(54.5 \%)$ did not respond at all (Figure 3). When asked about a favourite podcast or artist, a variety of responses were received. 20 students $(18.2 \%)$ listened to no specific podcast or artist, 15 students (13.6\%) listened to medical podcasts, 10 students (9\%) listened to Aspirant voice podcast (education podcast), 5 students (4.5\%) listened to business wars podcast and 60 students $(54.5 \%)$ did not respond at all (Figure 4).

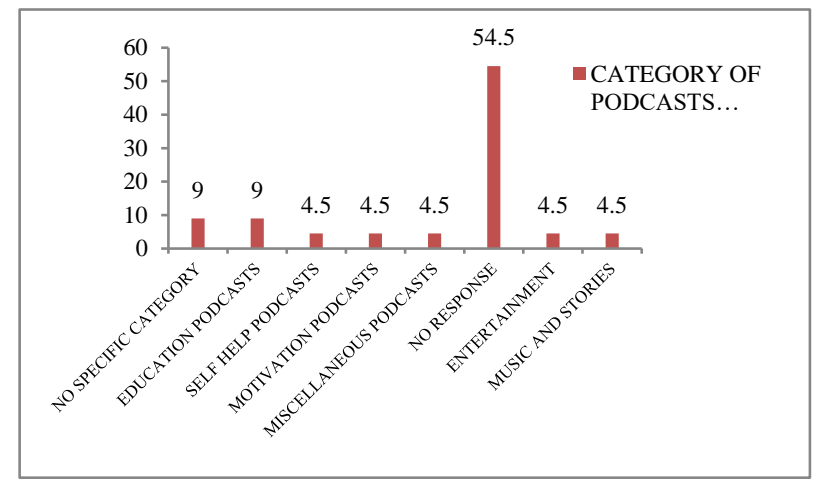

Figure 3: Category of podcast listened to by the participants.

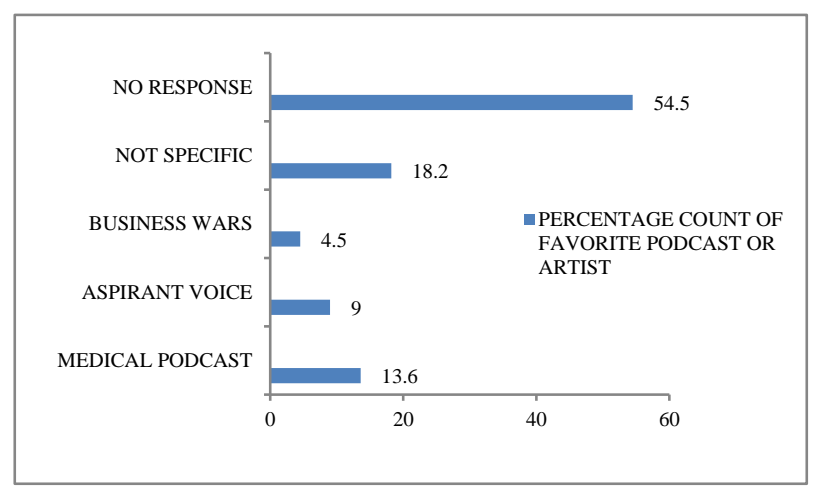

Figure 4: Specific names of favorite podcasts.

Students were asked to specifically name the Education podcast they knew and many responses were received.25 students $(22.72 \%)$ listened to medical podcasts like The legends of Surgery, 2 Docs talk, everyday emergency, pharmacology basics, JAMA medical news, etc.10 students $(9 \%)$ listened to the aspirant voice podcast for UPSC Students, 10 students (9\%) listened to the curiosity daily, a general knowledge podcast, 5 students (4.5\%) listened to the pomp show, a business podcast and 60 students $(54.5 \%)$ did not respond at all (Figure 5). 
Students were inquired if any of their quests or queries got resolved by hearing the podcasts, 85 students (77.27\%) replied "no", 15 students (13.6\%) replied "yes" and 10 students (9\%) did not reply at all.

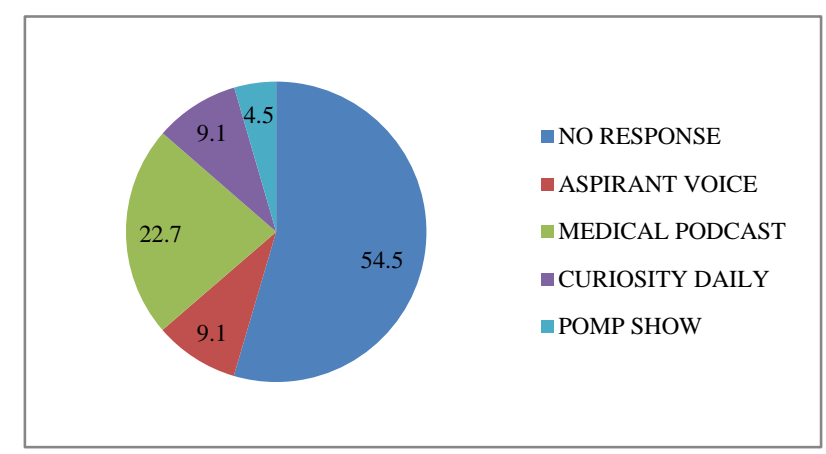

Figure 5: Specific education podcasts preferred by students.

Table 3: Whether podcasts be included in medical education curriculum.

\begin{tabular}{|ll|}
$\begin{array}{l}\text { Whether podcasts should be } \\
\text { included in the medical education } \\
\text { curriculum? }\end{array}$ & $\begin{array}{l}\text { Percentage of } \\
\text { responses }\end{array}$ \\
\hline Yes & 59.1 \\
\hline No & 27.27 \\
\hline No response & 13.63 \\
\hline
\end{tabular}

Knowledge of students' family members and friends about podcasts

This set consisted of questions 14 to 18 . These were framed to gather knowledge about podcasts in students' social circle comprising of friends and relatives. The aim is to know a little about students' background that affects his or her attitude and perception about this latest technology. First question in this regard was whether friends or family relatives of students listen to or know about podcasts. Maximum 60 students (54.5\%) replied "maybe" to this question. 30 students $(27.27 \%)$ replied "no" to this question. 15 students $(13.63 \%)$ replied "yes" to the question and 5 students $(4.54 \%)$ gave no response. When inquired about which podcast do the family relatives or friends of students listen to, 85 students $(77.27 \%)$ did not respond at all, 15 students $(13.63 \%)$ replied "no specific" podcast. 5 students (4.54\%) replied "education podcast" and 5 students (4.54\%) replied "biker's radio rodcast". Third question was asked to know whether students think podcasts are in trend nowadays. 65 students (59.1\%) replied "yes", 35 students $(31.8 \%)$ replied "no" and 10 students $(9 \%)$ did not respond at all. Next question was to know if students thought listening to podcast is better than watching a video for the same content. 50 students $(45.5 \%)$ replied "yes", 30 students $(27.3 \%)$ replied "no" and 30 students $(27.3 \%)$ did not respond at all. Students were asked about their opinion if podcasts should be included in education curriculum. 65 students $(59.1 \%)$ replied "yes", 30 students $(27.27 \%)$ replied "no", while 15 students (13.63\%) did not respond at all (Table 3). When students were asked if they used headphones to listen to podcasts, 60 students $(54.5 \%)$ replied "yes", 30 students $(27.27 \%)$ replied "no" and 20 students $(18.18 \%)$ did not respond at all.

\section{Students experience of side effects due to podcasts}

Students were asked to list a few side effects of podcasts. 60 students $(54.5 \%)$ agreed for "hearing problems". 20 students $(18.18 \%)$ agreed to "no" side effects of podcasts, 20 students $(18.18 \%)$ suggested "distraction of students from podcasts to music" and 10 students (9\%) felt that podcasts are "expressionless medium" (Figure 6).

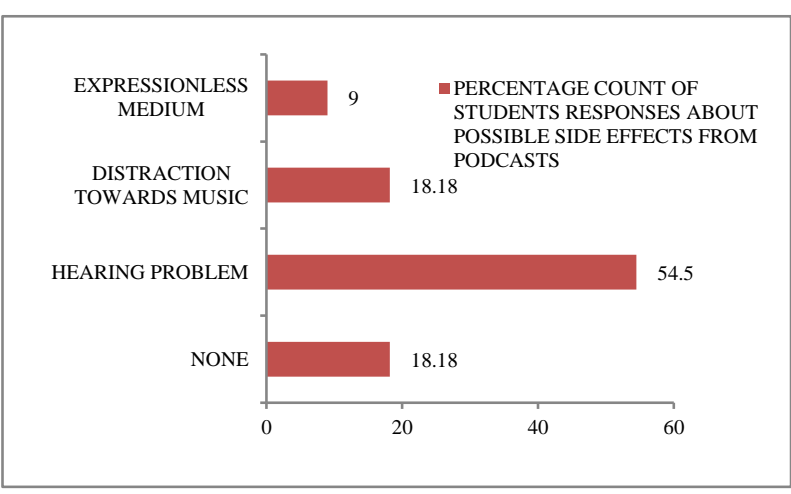

Figure 6: Possible stated side effects of podcasts by students.

\section{Students overall rating of podcasts}

Lastly students were asked to rate their overall experience of podcasts. 60 students $(54.5 \%)$ replied" doesn't matter", 30 students replied their experience as "excellent", 10 students (9\%) replied "good" and 10 students (9\%) replied "bad" (Figure 7).

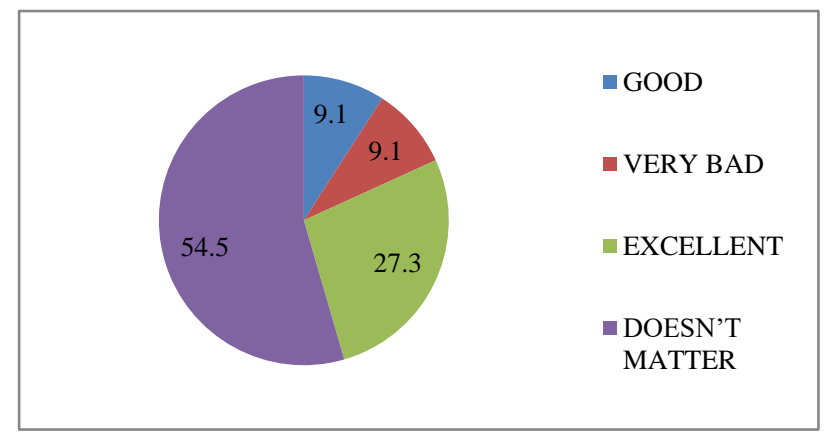

Figure 7: Overall rating of the podcasts experience by the students.

\section{DISCUSSION}

It was found that maximum students shared a true critical perspective of the newly inquired podcast technology. Their opinion is of great value in improving, shaping, 
modifying the education structure and strategy in a novel, modern, effective way. In our study, less than half of the total included students knew about the podcasts, the results are similar to studies by Aguiar et al. ${ }^{14}$ A major group of students prefer combined audio-video modes of education showing their proficiency with tech use, these results match with the studies by Prakash et al, Cho et al and Shantikumar et al. ${ }^{4,5,22}$ Sources of knowledge of podcasts was mainly friends, relatives followed by internet and social media showing a quite specific, friend and family centred interest and approach towards this novel technology of audio files. When inquired about the category and choice of podcasts students listen to, maximum students agreed to listen to education, self-help and motivational podcasts.

As far as name of podcast or artist was asked, only a few of the students listened to actual medical podcasts, major inclination was towards general education, knowledge and motivational podcasts. Minority of students actually got their queries and problems solved with this type of media, mainly they relied on books and other study material, teachers, coaching institutes, etc for their main education source, these results are the same as in studies by Aguiar et al and Jalali et al. ${ }^{3,14}$ This shows a little help is sought with audio files as far as medical studies are concerned. Other varieties of life learnings and interests are more explored with this media, this result was similar to study by Aguiar. ${ }^{14} \mathrm{~A}$ great degree of non-response shows a lack of interest and knowledge in this field of novel media and technology. With the second set of questions, a digging into surroundings and students' family background was made by questioning their family members etc about podcasts. Only a few students were confirmed that there were podcasts listened to at their homes, rest were either not sure or simply disagreed. When asked about the type of podcasts listened to, only a few agreed to education podcasts, mainly story based audio files were explored. This shows again a lack of enthusiasm and interest in audio mode of learning. It's still a great platform for entertainment and gaining diverse knowledge. The results match with the studies by Prakash et al, Goldman et al, Malecki et al and O'Connor et al. 4,17,21,23 Maximum students agreed that podcasts are in trend. This shows their welcome response to this media and technology and gives a scope for further modification and exploration to suit country or city or region-specific populations' topics of interests. This attributes to the numerous advantages of podcasts being of short length, these results are similar to studies by Jalali et al, Prakash et al and Berk et al. ${ }^{3,4,24}$ Podcasts serve to be mobile and student friendly, non-specific to time and place, results being similar to studies by Prakash et al, Alikhan et al, podcast article, Greenfield et al, O'connor et al and Jham et al. ${ }^{4,12,16,19,23,25}$ Podcasts help to promote logical and coherent thinking process, bridges the gaps between age old and new thoughts and perceptions and make students more skillful as these results also relate to studies done by Cho et al, Goldman et al, O'Connor et al, Fernandez et al and Popova et al. ${ }^{5,17,23,26,27}$ Only half of the students preferred audio mode over video learning, this shows that generally audio lags behind video modes of teaching, learning and education as also discussed in study by Shantikumar et al. ${ }^{22}$ Maximum students were of the opinion that podcast based audio teaching modes can be a part of the main teaching curriculum and they used headphones to listen to these audio files. This again shows a welcome response of students towards modifying teaching in medical colleges with proper and suitable use of novel technology. ${ }^{22}$ Study clearly indicates the use of novel audio media and technology named Podcasts as an add on learning tool along with traditional mode of teaching and lectures. The results match with most of the done studies in this context. ${ }^{3-5,11,16,17,19,20,23,26}$ That would enhance students' performance, interest and inspire him to be intuitive, creative and thoughtful besides regular cramming of medical sciences as also discussed in studies by Prakash et al, Kaplan et al, Podcast article, Minter et al and Shantikumar et al. ${ }^{4,11,16,18,22}$ A research based bent of mind is nurtured via such attempts in curriculum. Teachers can adopt several methods and ways to include podcasts along with normal

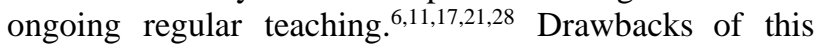
audio technology cannot be ignored as in place of education strategy it may be exploited as a musical tool only. ${ }^{11,12,17}$ It is surely not for low tech proficient students as also discussed in studies by Patrick et al and Meade et al. ${ }^{6,15}$ The solo potential of Podcasts in education and teaching still lacks support and evidence., ${ }^{4,5,15,16,22}$

\section{Limitations}

Convenient random sampling method was adopted which is a non-probability sampling method which does not give equal chance to all the targeted subjects to participate in the study. A possibility of bias exists. The results of survey cannot be generalized over the population as a whole

\section{CONCLUSION}

A broad mindedness and generous attitude welcomes change for development and betterment of the present scenario and strategies. That is what is required and such educational reforms are always paving the way to improve learning and bring about positive development, an enlightened future and overall progress of the nation. Podcasts, though a good idea to be included in the main curriculum not as main mode rather an add-on (complementary) tool to make teaching more interesting, elaborative and student friendly. For elaborating the study results, more students can be included from different cities; especially opinions from few rural cities can be added, compared and generalized to suit the whole population's common interest. By improving sampling methods, bias can be reduced and more students get a chance to participate in the study. Lack of enough support and flexibility may demoralize the whole concept. There still exists a wide room for research and evidence-based use of this technology and much work needs to be done 
to actually add a new brick in the current structure of medical education.

Funding: No funding sources

Conflict of interest: None declared

Ethical approval: Not required

\section{REFERENCES}

1. Podcast. Available at: https://en.wikipedia.org/wiki/ Podcast\#: :text=\%22Podcast $\% 22 \% 20$ is $\% 20 \mathrm{a} \% 20 \mathrm{p}$ ortmanteau $\% 2 \mathrm{C}$, article $\% 20$ for\%20The\%20Guardia n\%20newspaper. Accessed on 20 August 2021.

2. Oxford dictionary names "podcast" 2005 word of the year. Available at: https://www.wired. com/2005/12/oxford-dictiona/. Accessed on 20 August 2021.

3. Jalali A, Leddy J, Gauthier M, Sun R, Hincke M, Carnegie J. Use of podcasting as an innovative asynchronous e-learning tool for students. Edu Rev. 2011;6:741-8.

4. Prakash S, Muthuraman N, Anand R. Short-duration podcasts as a supplementary learning tool: perceptions of medical students and impact on assessment performance. BMC Med Educ. 2017;1:167.

5. Cho D, Cosimini M, Espinoza J. Podcasting in medical education: a review of Literature. Korean J Med Educ. 2017;29(4):229-39.

6. Patrick MD, Stukus DR, Nuss KE. Using podcasts to deliver pediatric educational content: Development and reach of PediCast CME. Digital Health. 2019;5:1-9.

7. Little A, Kalnow A, Walker AR, Capone P. Podcasting in medicine:the current content by emergency medicine subspeciality. Cureus. 2020;12(8):e9848.

8. Hurst EJ. Podcasting in medical education and healthcare. J Hospital Librarianship. 2019;19(3):214-26.

9. Rodman A, Trivedi S. Podcasting: a roadmap to the future of medical education. Nephrol. 2020;40(3):279-83.

10. Lomayesva NL, Martin AS, Dowley PA, Davies NW, Olyha SL, Wijesekera TP. Five medical education podcasts you need to know. Yale J Biol Med. 2020;93(3):461-6.

11. Kaplan H, Verma D, Sargsyan Z. What traditional lectures can learn from Podcasts. J Grad Med Educ. 2020;12(3):250-3.

12. Alikhan A, Kaur RR, Feldman SR. Podcasting in dermatology education. J Dermatol Treat. 2010;21(2):73-9.

13. Abreu DV, Tamura TK, Sipp JA, Keamy DJ, Eavey RD. Podcasting:a contemporary patient education. Ear Nose Throat J. 2008;87(4):208-10.
14. Aguiar CA, Carvalho AA. Exploring podcasting in heredity and evolution teaching. Biochem Mol Biol Educ. 2016;44(5):429-32.

15. Meade O, Bowskill D, Lymn JS. Pharmacology podcasts: a qualitative study of non medical prescribing students use, perceptions and impact on learning. BMC Med Educ. 2011;11:2.

16. Podcasts in medical education. Available at: https://guides.himmelfarb.gwu.edu/podcasts.

Accessed on 20 August 2021.

17. Goldman T. The impact of podcasts in education. Pop Culture Intersect. 2018;5:29.

18. Minter DJ, Geha R, Manesh R, Dhaliwal G. The future comes early for medical educators. J Gen Intern Med. 2015;36(5):1400-3.

19. Greenfield S. Podcasting a new tool for student retention?. J Nurs Edu. 2010;50(2):52-9.

20. Whitehead DAJ, Bray D, Harries M. Not just music but medicine. Podcasting surgical procedures in otolaryngology. Clin Otolaryngol. 2007;32(1):3-6.

21. Malecki SL, Quinn KL, Zilbert N, Razak F, Ginsburg S, Verma AA, Melvin L. Understanding the use and perceived impact of a medical podcast: Qualitative Study. JMIR Med Educ. 2019;5(2):e12901.

22. Shantikumar S. From lecture theatre to portable media: students' perceptions of an enhanced podcast for revision. Med Teach. 2009;31(6):535-8.

23. O'Connor S, Daly CS, MacArthur J, Borglin G, Booth RG. Podcasting in nursing and midwifery education: An integrative review. Nurse Educ Pract. 2020;47:102827.

24. Berk J, Trivedi SP, Watto M, Williams P, Centor R. Medical education podcasts:where we are and questions unanswered. J Gen Intern Med Epub. 2020;2:45.

25. Jham BC, Duraes GV, Strassler HE, Sensi LG. Joining the podcast revolution. J Dent Educ 2008; 72(3):278-81.

26. Fernandez V, Jose PS, Sallan M. Podcasting:a new technological tool to facilitate good practice in higher education. Comp Edu. 2009;53(2):385-92.

27. Popova A, Edirisingha P. How can podcasts support engaging students in learning activities?. ProcediaSocial Behav Sci. 2010;2(2):5034-8.

28. Teachers are turning to podcasts as instructional tool. Available at: https://www.edweek. org/teaching-learning/teachers-are-turning-topodcasts-as-an-instructional-tool/2019/02. Accessed on 20 August 2021.

Cite this article as: Vijay R, Gupta N. Podcasts as emerging tool for medical education: a critical perspective. Int J Basic Clin Pharmacol 2021;10:1368-73. 